\title{
EL CONSENTIMIENTO LIBRE: LA TRAMPA DE LA EXPLOTACIÓN FEMENINA EN LA MATERNIDAD SUBROGADA
}

\section{FREE CONSENT: THE TRAP OF FEMALE EXPLOITATION IN SURROGATE MOTHERHOOD}

\author{
Leticia Cabrera Caro*
}

\begin{abstract}
On September 2017, Ciudadanos parliamentary group, presented a law proposal regarding the subrogate gestation right to the Spanish Congress.

This proposal consecrates acknowledgement or altruism as its main principle, that along with the previously informed agreement of the pregnant woman, attempts to transmute the subrogate gestation issue as an act of solidarity and thankfulness completely harmless and sterile. Nevertheless, the mere impossibility that the pregnant mother could revoke her consent, stated at the beginning of the relationship, shows the disguise in which it is attempted to hide her exploitation in this assisted reproduction technique.
\end{abstract}

Keywords: Surrogate motherhood; pregnancy by substitution; regulation; consent; human dignity.

RESUMEN: La Proposición de Ley reguladora del derecho a la gestación por subrogación, presentada por el Grupo Parlamentario Ciudadanos al Congreso, en septiembre de 2017, consagra la gratuidad o el altruismo como principio básico que, junto al consentimiento informado y libre de la mujer gestante, intenta convertir a la maternidad subrogada en un acto de solidaridad y generosidad, inocuo y aséptico. Sin embargo, la imposibilidad de que la madre gestante pueda revocar su consentimiento, emitido al principio de la relación, muestra la trampa con la que se intenta ocultar su explotación en esta técnica de reproducción humana asistida.

Palabras clave: Maternidad subrogada; gestación por sustitución; regulación; consentimiento; dignidad humana.

\section{INTRODUCCIÓN}

La maternidad subrogada ${ }^{1}$ es una técnica de reproducción humana asistida por medio de la cual, como es sabido, una mujer se presta a gestar el hijo de otros, renunciando,

* Profesora Contratada Doctora, Departamento de Derecho Público, Filosofía del Derecho, Universidad de Cádiz. Dirección postal: Facultad de Derecho. Campus universitario de Jerez. Avda. de la Universidad, s/n, 11405 Jerez de la Frontera, Cádiz. Dirección electrónica: leticia.cabrera@uca.es. Un resumen de este estudio fue presentado como ponencia al Congreso Internacional Derechos Humanos y Género, celebrado en Valencia, los días 3 y 4 de mayo de 2017, con el título "La maternidad subrogada en el contexto del postfeminismo de género".

1 Son muchas las expresiones que se emplean para referirse a esta técnica: maternidad subrogada; gestación por sustitución; explotación reproductiva de mujeres; madres, úteros o vientres de alquiler; madres sustitutas o subrogación uterina, etc. El empleo de una u otra terminología no es neutro, sino que puede esconder una clara intencionalidad ideológica, como se ha constatado por distintos sectores. Ver, por ejemplo, VeLA, (2017) pp. 
tras el parto, a cualquier tipo de relación jurídica o filiación sobre él. Esta posibilidad, que actualmente ha provocado un gran debate intelectual acerca de sus implicaciones tanto éticas como jurídicas, no es, ni mucho menos, novedosa o propia de nuestra era. En el Antiguo Testamento, en la época precristiana, ya encontramos referencias a ciertas prácticas que podrían asimilarse a la maternidad subrogada, en los relatos sobre la infertilidad de Sara y Raquel.

Sara era la mujer de Abraham. Después de diez años de convivencia, no había quedado embarazada aún y, apesadumbrada por ello, le ofreció a su marido la posibilidad de dormir con su esclava Agar para que tuvieran descendencia a través de ella. Fruto de esa unión nació Ismael, cuando Abraham contaba ya con ochenta y seis años ${ }^{2}$. El caso de Raquel es muy parecido. Ella estaba casada con Jacob pero aún no habían tenido hijos. Al quedar la hermana de Raquel embarazada, siente envidia y le propone a Jacob concebir un hijo a través de su esclava Bilá. De esa unión nació un niño al que llamaron Dan ${ }^{3}$ Eleonora Lamm, en un extenso estudio sobre la gestación por sustitución publicado en 2012, se refiere al hecho de que estas prácticas se encuentren recogidas en el Antiguo Testamento como una especie de visto bueno ético: "Si bien la gestación por sustitución se nos presenta como una figura de la modernidad, lo cierto es que sus primeros antecedentes se encuentran en el antiguo testamento, lo que me provoca el primer cuestionamiento: Si el Dios del Antiguo Testamento no veía nada malo en la subrogación [...] si los propios profetas bíblicos recurrían a madres de alquiler [...] ¿Por qué nos cuesta tanto a nosotros aceptarla?”“4. En realidad, en estos pasajes no hay un juicio de moralidad por parte de Dios, respecto a lo que han propiciado Sara y Raquel. En ellos, solo se reflejan unos hechos, sin entrar a valorarlos moralmente. Teniendo en cuenta que en aquella época era lícita la esclavitud, no podemos sorprendernos de que se acepten sin reproche moral las consecuencias de la misma. No hay ninguna razón para considerar peor la cesión sexual de Agar y Bilá a sus correspondientes amos, que su propia condición de esclavas.

Por otra parte, la etnóloga $\mathrm{M}^{\mathrm{a}}$ Eugenia Olavarría, citando a la antropóloga francesa Françoise Héritier, asimila la maternidad subrogada con una práctica antigua, ya existente en Roma: “[...] los úteros subrogados existieron en la Roma antigua mediante la institución del ventrum locare $[\ldots]^{5}$. Por esta institución, el paterfamilias cedía su esposa temporalmente a otro para que pudiera engendrar un hijo. Considerando que en Derecho romano regía el principio de partus sequitur ventrem, en virtud del cual, "el parto de la madre esclava sigue la condición de esta, sin considerar la condición o estado del padre”, creo que

3-4; Albert (2017) p. 178 o López Guzmán (2017) p. 199. Por nuestra parte, emplearemos preferentemente la expresión gestación por sustitución porque es la expresión legal, utilizada por el art. 10 de la LEY 14/2006, de 26 de mayo, sobre técnicas de reproducción humana asistida, y maternidad subrogada o gestación por subrogación, como sinónimos.

2 Gén., 16.

3 Gén., 30.

4 LAMM (2012a) p. 4.

5 Olavarría (2002) p. 109.

${ }^{6}$ Romero (1895) p. 297. En este lugar, el autor se basa en el comentario que Ulpiano realiza a Sabino en relación al usufructo del parto. Para Ulpiano, el parto de una esclava no es un fruto porque "un hombre no puede 
sería más acertado equiparar el ventrum locare con una fecundación con donante de semen que con una maternidad subrogada.

En todo caso, con independencia del origen histórico de esta práctica, parece patente que la preocupación por la reproducción y la conservación del linaje ha sido una constante en la Historia de la Humanidad. Actualmente, esta preocupación se ve aliviada, respecto a otras épocas históricas, por el avance de las técnicas de reproducción asistida, que permiten separar la sexualidad de la gestación 7 . Lejos de la crudeza descrita por la escritora canadiense Margaret Atwood en el "Cuento de la criada", de la evidente situación de explotación en la que se encuentran las esclavas de Sara y Raquel, o de la incapacidad de elección de una patricia romana, la disociación entre gestación y sexualidad propiciada por las actuales técnicas de reproducción humana asistida, permite contemplar la maternidad subrogada como un acto de generosidad y solidaridad, como un remedio para ayudar al que, por distintas razones, no puede ver colmado su deseo de ser padre o madre.

Este es el sentido de la Proposición de Ley reguladora del derecho a la gestación por subrogación (a partir de aquí PLDGS), presentada por el Grupo Parlamentario Ciudadanos al Congreso español, en septiembre de 2017. En esta Proposición se consagra la gratuidad o el altruismo como principio básico que, junto al consentimiento informado y libre de la mujer gestante, intenta convertir a la maternidad subrogada en algo inocuo y aséptico. No obstante, en este artículo se pretende argumentar que el hecho de que haya consentimiento y gratuidad por parte de la mujer gestante, no oculta la explotación que sufre la misma con esta técnica.

\section{REGULACIÓN DE HECHOY REGULACIÓN DE DERECHO}

Como hemos afirmado al principio, actualmente, asistimos a un encendido debate acerca de las implicaciones éticas y jurídicas de la maternidad subrogada. En España, este debate se intensificó, sobre todo, a partir de la famosa Sentencia del Tribunal Supremo, de 6 de febrero de 2014, que resolvía un recurso de casación, y del Auto del mismo Tribunal, de 2 de febrero de 2015 (Pleno Sala Civil), que resolvía un recurso de nulidad de las actuaciones interpuesto por la defensa como consecuencia de la aparición, con posterioridad al recurso de casación, de dos sentencias del Tribunal Europeo de Derechos Humanos en casos de maternidad subrogada: Mennenson c. Francia (Ap. No 65192/11) y Labasse c. Francia (Ap. No 65941/11). En marzo de 2016, el Tribunal Constitucional no admitió a trámite el recurso de amparo presentado frente a la desestimación del recurso de casación y,

tener el usufructo de otro hombre". Dig. 7,1,68.

7 La auténtica dimensión de esta disociación producida por las nuevas tecnologías reproductivas, no puede comprenderse sin tener en cuenta el avance de las técnicas de contracepción de los años 80. "Los anticonceptivos orales establecieron una de las condiciones de existencia para lo que puede denominarse la liberación entre sexualidad y procreación. Las técnicas de reproducción asistida hacen de esta liberación metafórica una disociación literal”. Olavarría (2002) p. 110.

8 ATwOod (1985). La edición española es de Salamandra, 2017. Esta novela se ha adaptado recientemente a la televisión en formato serie y ha obtenido un notable éxito entre la crítica y la audiencia. 
con esto, se ponía fin a un litigio iniciado ocho antes, el conocido como "Caso cero" de la maternidad subrogada en España?

Sin embargo, el fin de este procedimiento no ha significado, ni mucho menos, el fin del debate ni la solución a los conflictos planteados. De hecho, desde 2009, se han venido produciendo desencuentros entre la doctrina del Tribunal Supremo y la Dirección General de los Registros y del Notariado en cuanto a la inscripción de la filiación de los niños habidos en el extranjero como consecuencia de un contrato de subrogación ${ }^{10}$. La Fiscalía, siguiendo la doctrina del Tribunal Supremo expuesta en las resoluciones anteriormente citadas, se opone a la inscripción del nacimiento y filiación de estos niños por considerarlas contrarias al orden internacional español, según la declaración de nulidad de este tipo de contratos contenida en el artículo 10.1 de la Ley 14/2006, de 26 de mayo, sobre técnicas de reproducción humana asistida (en adelante, LTRHA). La Dirección General de los Registros y del Notariado, por su parte, permite la inscripción siempre y cuando, según su Instrucción de 5 de octubre de 2010, dicha filiación a favor de los padres comitentes haya sido reconocida por una autoridad judicial, en lugar de por una mera certificación de la autoridad registral, como indicaba en su Instrucción anterior, de 18 de febrero de 2009, anulada por el Tribunal Supremo ${ }^{11}$.

Estos desencuentros, esta forma distinta de abordar el problema, no han hecho más que aumentar e intensificar, de un lado, la inseguridad jurídica de quienes recurren a esta técnica para ser padres en el extranjero y, de otra, el debate acerca de la necesidad de una adecuada regulación de esta cuestión.

Ciertamente, la situación actual es insostenible o, en palabras de Vicente Bellver, "irregular y caótica" 12 y está motivada, a mi juicio, sobre todo, por la incompleta, deficiente, irregular o, en todo caso, mejorable, técnica legislativa empleada por la LTRHA que produce, en la práctica, lo que muchos han calificado como una legalización "de facto" de la gestación por sustitución. Esta legalización de hecho se observa claramente en dos supuestos: en los casos de inscripción de la filiación de hijos nacidos por un contrato de gestación en el extranjero y en los casos de reconocimiento de prestaciones por maternidad, causada igualmente por una gestación por sustitución ${ }^{13}$.

\footnotetext{
9 Para conocer los detalles de este caso y su secuencia procesal durante los ocho años que duró el litigio, puede consultarse Albert (2016) pp. 1-19.

10 González (2017) p. 2; Bellver (2017) p. 3.

${ }^{11}$ Ver, por ejemplo, NúŃEZ et al. (2015) p. 245. Durante el año judicial 2015, se han tramitado en España doce expedientes de inscripción de nacimiento de menores nacidos por contratos de este tipo en Rusia y en Estados Unidos. En el año judicial 2016, los expedientes tramitados (por nacimientos acaecidos en Rusia, Ucrania, Méjico y Estados Unidos) han sido nueve. En ambos casos, los recursos interpuestos contra los Autos denegatorios de la Fiscalía han sido dos, pendientes de resolución, según las respectivas Memorias de la Fiscalía General del Estado 2016 y 2017, pp. 499 y 550, respectivamente. En la memoria de 2018, se reitera la posición de la fiscalía respecto a años anteriores.

12 Bellver (2017) p. 230.

13 Ver GonzÁlez (2017) pp. 117-131. También en Aragón (2017) pp. 6-12.
} 


\subsection{INSCRIPCIÓN DE LA FILIACIÓN DE HIJOS NACIDOS POR GESTACIÓN SUBROGADA EN EL EXTRANJERO}

En este supuesto, la legalización de facto de la maternidad subrogada se produce porque el artículo 10.1 de la LTRHA no prohíbe taxativamente la gestación por subrogación, ni la sanciona administrativamente, tan solo se limita a declarar la nulidad de pleno derecho de los contratos, con o sin precio, celebrados a tal fin. Pero la simple declaración de nulidad, por sí sola, no es suficiente para impedir que esos contratos celebrados y nulos produzcan unos efectos que, por su propia naturaleza, no pueden retrotraerse a la situación inicial. Me refiero, concretamente, a que la primera consecuencia irreversible de ese contrato nulo es el nacimiento de un niño que, lógicamente, debe ser protegido por el Ordenamiento jurídico ${ }^{14}$. El legislador, consciente de ello y a pesar de la inicial declaración de nulidad, reconoce el vínculo paternofilial que en todo caso existe y no puede obviarse, en los apartados $2^{\circ}$ y $3^{\circ}$ del mismo art. 10.

Así, en el art. 10.2 de la LTRHA, el legislador consolida el principio de la determinación de la filiación materna a través del parto en los supuestos de gestación por subrogación (se trata del principio "mater semper certa est" ${ }^{15}$ ). Esta determinación legal de la maternidad por el parto, debe interpretarse como un efecto de la declaración de nulidad, tal y como establece el artículo 6.3 del Código Civil, que señala: "Los actos contrarios a las normas imperativas y a las prohibitivas son nulos de pleno derecho, salvo que en ellas se establezca un efecto distinto para el caso de contravención" ${ }^{16}$. En los supuestos de gestación por subrogación, con o sin precio, el primer efecto de la declaración de nulidad previsto por el legislador, es la necesaria atribución de la filiación materna a quien lo ha dado a luz, con independencia de que sea o no su madre biológica. Es, por tanto, una consecuencia, prevista por el legislador, de la nulidad del contrato de gestación.

Por su parte, el apartado tercero del mismo art. 10 de la LTRHA, determina el régimen de filiación paterna: "Queda a salvo la posible acción de reclamación de la paternidad respecto del padre biológico, conforme a las reglas generales" 17 . Podría interpretarse este apartado como una excepción a la nulidad del contrato, sin embargo, se trata más bien de la necesidad de proveer de tutela parental al niño nacido como consecuencia de un contrato nulo. Así, se atribuye la filiación paterna al varón que haya aportado su material genético pero, a la pareja de este, solo le quedará la posibilidad de iniciar un trámite de adopción del mismo.

Esta regulación hubiera sido suficiente, por sí sola, de no existir la posibilidad de realizar legalmente este tipo de reproducción humana asistida en países extranjeros. En

\footnotetext{
14 “(...) la inseguridad jurídica que supone la prohibición o la indefinición legal en los países de origen de los padres/madres intencionales, está planteando reiterados conflictos a la hora de inscribir al recién nacido/ a en sus respectivos registros civiles nacionales. Un contexto en el que puede no operar ni el ius soli ni el ius sanguini (ni el derecho del suelo o del lugar, ni el de la sangre) y en el que la criatura concebida corre el riesgo de no tener tutela parental y ser apátrida”. NuÑo (2016) p. 6.

15 Este es un principio ancestral de Derecho Romano, que aparece recogido en Dig. 2,4,5. Nuestro Ordenamiento, desde siempre, se ha hecho eco de él y, de hecho, a pesar de que la LTRHA ha sido reformada en varias ocasiones, la prohibición de la gestación por sustitución y la determinación de la filiación en favor de la mujer que alumbra, se ha mantenido intacta desde el primer momento de su vigencia.

16 Artículo 10.2 de la LTRHA.

17 Artículo 10.3 de la LTRHA.
} 
otras palabras, el problema surge cuando los padres comitentes, para soslayar la legislación española, acuden al extranjero y esgrimen el contrato de gestación por subrogación para que se determine, en el Registro Civil Consular, la filiación a su favor. Porque, como ya hemos explicado, en los casos que la realización de esos contratos requiera la intervención de una autoridad judicial en los países de origen, la Dirección General de los Registros y del Notariado (en adelante, DGRN), aplicando la Instrucción de 5 de octubre de 2010, ordena la inscripción del nacimiento y de la filiación a favor de los padres comitentes. En concreto, en el art. 1 de la citada Instrucción, se establece: "La inscripción de nacimiento de un menor, nacido en el extranjero como consecuencia de técnicas de gestación por sustitución, solo podrá realizarse presentando, junto a la solicitud de inscripción, la resolución judicial dictada por Tribunal competente en la que se determine la filiación del nacido" ${ }^{18}$.

El problema reside en que, para la DGRN, el encargado del Registro Civil español solo debe realizar determinados controles incidentales, formales, para comprobar si dicha resolución judicial extranjera puede ser reconocida en España a efectos registrales ${ }^{19}$. No le correspondería al encargado del Registro Civil valorar si dicha resolución judicial provoca o no efectos contrarios al Ordenamiento jurídico español como, por el contrario, sostiene el Tribunal Supremo en su Sentencia de 6 de febrero de 2014.

Por tanto, la DGRN, al permitir la inscripción de la filiación que determine la resolución judicial extranjera, está permitiendo una legalización de hecho de la gestación por sustitución, al reconocer efectos jurídicos a esos contratos celebrados en el extranjero pero que son nulos en España. Es un claro supuesto de fraude de ley, por la vía administrativa ${ }^{20}$, porque es la propia Dirección General la que legaliza sin legalizar ${ }^{21}$, reconociendo, de hecho, unos los efectos civiles en la determinación de la filiación materna que son contrarios al tenor literal del art. 10.2: "La filiación de los hijos nacidos por gestación de sustitución será determinada por el parto".

Pero esta situación de insuficiencia o de irregularidad en la técnica legislativa de la LTRHA se evidencia aún más si contemplamos otro supuesto. En el caso de que los que hayan acudido al extranjero para realizar este tipo de contrato fueran una pareja heterosexual, que hayan aportado cada uno de los dos su propio material genético, el art. 10.2 de

\footnotetext{
18 Artículo 1 de la Instrucción de 5 de octubre de 2010, de la Dirección General de los Registros y del Notariado, sobre régimen registral de la filiación de los nacidos mediante gestación por sustitución. BOE núm. 243, de 7 de octubre de 2010 .

19 Expresamente, establece que: "En dicho control incidental deberá constatar: a) La regularidad y autenticidad formal de la resolución judicial extranjera y de cualesquiera otros documentos que se hubieran presentado b) Que el Tribunal de origen hubiera basado su competencia judicial internacional en criterios equivalentes a los contemplados en la legislación española c) Que se hubiesen garantizado los derechos procesales de las partes, en particular, de la madre gestante d) Que no se ha producido una vulneración del interés superior del menor y de los derechos de la madre gestante. En especial, deberá verificar que el consentimiento de esta última se ha obtenido de forma libre y voluntaria, sin incurrir en error, dolo o violencia y que tiene capacidad natural suficiente e) Que la resolución judicial es firme y que los consentimientos prestados son irrevocables, o bien, si estuvieran sujetos a un plazo de revocabilidad conforme a la legislación extranjera aplicable, que este hubiera transcurrido, sin que quien tenga reconocida facultad de revocación, la hubiera ejercitado”. Directriz primera, 3 de la Instrucción de 5 de octubre de 2010 de la DGRN, cit.

20 Albert (2017) p. 190.

21 Serrano (2017) p. 222. También en Aragón (2017) p. 28.
} 
la LTRHA sencillamente impide la determinación de la filiación biológica materna. La madre biológica, en este caso, solo puede iniciar un expediente de adopción del que es, genéticamente, su hijo, salvo que aporte una resolución judicial en el momento de la inscripción consular, como hemos explicado anteriormente.

Si tenemos en cuenta que el art. 7.3 de la misma ley establece la denominada "doble maternidad legal", es decir, la posibilidad de que la mujer casada con otra mujer manifieste su voluntad de determinar la filiación a su favor del hijo nacido de su cónyuge, es difícil entender la racionalidad de esta medida y su consonancia con el mantenimiento del principio romano "mater semper certa est". No existe ninguna razón jurídica para que, en un caso (el de parejas homosexuales femeninas), la simple voluntad de considerar al hijo como propio, baste para determinar la filiación natural de las dos madres respecto al hijo y, en otros casos (parejas heterosexuales con aportación de material genético), a la madre biológica solo le quede la posibilidad de iniciar una adopción. Solo podríamos explicarlo teniendo presente la voluntad del legislador de considerar estos contratos nulos de pleno derecho, por lo que la prohibición en estos supuestos de reconocer la filiación de la madre genética, no sería más que la sanción o la consecuencia jurídica de la realización de un acto no admitido por la ley.

No obstante, algunos entienden que es una articulación discriminatoria ${ }^{22}$ y abogan por añadir, en el tradicional sistema de filiación español, junto a la filiación natural o biológica (matrimonial o extramatrimonial) y adoptiva, una tercera clase: la filiación volitiva, basada en la simple manifestación de la voluntad de querer ser padre o madre: "Ser padre o madre es mucho más que un vínculo genético o biológico: es querer ser padre o querer ser madre; y eso es precisamente lo que permite la filiación derivada de TRA [técnicas de reproducción asistida] al prever un sistema basado en la voluntad"23. A efectos registrales, las consecuencias de admitir este tipo de filiación, son claras: en los supuestos de inscripción de la filiación natural o biológica (matrimonial o extramatrimonial) y de inscripción de filiación adoptiva, solo cabrían dos asientos registrales: el progenitor A y el progenitor B; mientras que, en el caso de una hipotética filiación volitiva, serían posibles tantos asientos como personas deseosas de ser considerados padres o madres existan. Tendríamos, pues, filiaciones de tres, cuatro o hasta cinco progenitores de un mismo niño ${ }^{24}$.

22 Por ejemplo, LAmm (2012b) pp. 84-85 y NúÑEz et ali. (2015) p. 240.

23 LAm (2012b) p. 90. Un poco antes, en el mismo lugar, ha explicado que: "Las TRA [técnicas de reproducción asistida] afectan el concepto de familia y seguramente continuarán afectándolo de maneras que aún no se pueden imaginar. Bajo estas circunstancias, considero que lo mejor es utilizar la noción de voluntad como la base o punto de partida para cualquier concepto de familia que pueda surgir.

Las TRA no solo permiten que quien quiere (sic.) ser padre o madre pueda serlo, habiendo brindado una solución a muchos supuestos de infertilidad; sino que además permiten que madre o padre sea entonces quien ha querido serlo".

24 En 2015, en Argentina, se autorizó la inscripción registral de la triple filiación de un niño que había nacido con donante de semen en el seno de una pareja homosexual femenina. El padre biológico, amigo de la pareja, quiso estar también presente en la crianza del hijo y, a través de la triple inscripción de la filiación, consiguió el reconocimiento legal de su pretensión. Ver https://elpais.com/internacional/2015/4/24/actualidad/1429827035_368004.html. Fecha de consulta: 11 de febrero de 2019. 


\subsection{RECONOCIMIENTO DE LAS PRESTACIONES SOCIALES POR MATERNIDAD DE HIJOS}

NACIDOS DE GESTACIÓN POR SUSTITUCIÓN EN EL EXTRANJERO

En este segundo supuesto, la legalización de facto se produce cuando se reconocen judicialmente prestaciones por maternidad a los padres subrogantes. Como es sabido, nuestro sistema de Seguridad Social reconoce unas prestaciones económicas destinadas a proteger determinadas situaciones como la maternidad biológica, la adopción y el acogimiento ${ }^{25}$. En ningún momento, nuestro legislador se ha referido expresamente a la maternidad subrogada en este contexto, no obstante, en virtud del art. 2.2 del RD 295/2009, de 6 de marzo, se consideran jurídicamente equiparables a la adopción y al acogimiento, "aquellas instituciones jurídicas declaradas por resoluciones judiciales o administrativas extranjeras", cuya finalidad y efectos jurídicos sean los previstos para la adopción y el acogimiento ${ }^{26}$. La interpretación acerca de la asimilación de la gestación por subrogación a esta figura ha dado lugar a conflictos que, inicialmente, eran fallados en contra por el Instituto Nacional de Seguridad Social (INSS). Los recursos contra estas decisiones del INSS se han resuelto de una forma no uniforme, si bien en su mayoría favorables al reconocimiento de la prestación por maternidad cuando esta traía causa de un contrato de gestación celebrado en el extranjero $^{27}$. Ante esta situación, el INSS interpuso un recurso de casación para la unificación de la doctrina ante el Tribunal Supremo, resuelto en la Sentencia de 25 de octubre de 2016, cuyos argumentos han sido reiterados posteriormente por la Jurisprudencia de lo Social. La existencia de tres votos particulares a los que se adhieren otros tres magistrados, pone de manifiesto la profunda complejidad del debate en este asunto. La Sentencia se posiciona a favor del reconocimiento de la prestación por maternidad al padre biológico de dos niñas nacidas en la India gracias a un "vientre de alquiler", y lo hace amparándose en el argumento de la existencia de una situación de necesidad real de protección, con independencia de que esta situación haya devenido de un contrato nulo en España. Concretamente, afirma: "[...] que una Ley Civil prescriba la nulidad del contrato de maternidad por subrogación no elimina la situación de necesidad surgida por el nacimiento del menor y su inserción en determinado núcleo familiar; y tal situación de necesidad debe ser afrontada desde la perspectiva de las prestaciones de Seguridad Social procurando que esos hijos no vean mermados sus derechos. Y aquí nos encontramos con un contrato de maternidad por su-

\footnotetext{
25 Artículo 177 del Real Decreto Legislativo 8/2015, de 30 de octubre, por el que se aprueba el texto refundido de la Ley General de la Seguridad Social: "A efectos de la prestación por maternidad prevista en esta sección, se consideran situaciones protegidas la maternidad, la adopción, la guarda con fines de adopción y el acogimiento familiar, de conformidad con el Código Civil o las leyes civiles de las comunidades autónomas que lo regulen, siempre que, en este último caso, su duración no sea inferior a un año, durante los períodos de descanso que por tales situaciones se disfruten, de acuerdo con lo previsto en los apartados 4, 5 y 6 del artículo 48 del texto refundido de la Ley del Estatuto de los Trabajadores, y en el artículo 49. a) y b) de la Ley 7/2007, de 12 de abril, del Estatuto Básico del Empleado Público".

26 El art. 2.2 del RD 295/2009, de 6 de marzo, por el que se regulan las prestaciones económicas del sistema de la Seguridad Social por maternidad, paternidad, riesgo durante el embarazo y riesgo durante la lactancia natural, establece: "Se considerarán jurídicamente equiparables a la adopción y al acogimiento preadoptivo, permanente o simple, aquellas instituciones jurídicas declaradas por resoluciones judiciales o administrativas extranjeras, cuya finalidad y efectos jurídicos sean los previstos para la adopción y el acogimiento preadoptivo, permanente o simple, cuya duración no sea inferior a un año, cualquiera que sea su denominación”.

27 Aragón (2017) p. 11.
} 
brogación que es nulo pero que ha desplegado sus efectos, en particular los que interesan: inserción de las menores nacidas en el núcleo familiar de quien solicita las prestaciones por tal motivo" 28 . Esta situación, junto al principio de la consideración primordial del interés superior del menor, determina el fallo.

No obstante, los votos particulares que acompañan a esta Sentencia rechazan abiertamente esta argumentación, que se considera una extralimitación del poder judicial. Y ello, sobre todo por dos motivos:

En primer lugar, porque el principio invocado de la consideración primordial del interés del menor, según la STS de 6 de febrero de 2014, sirve para “[...] interpretar y aplicar la ley y colmar sus lagunas, pero no para contrariar lo expresamente previsto en la misma”. Se añade que: "No hacerlo así, podría llevar a la desvinculación del juez del sistema de fuentes, que es contraria al principio de sujeción al imperio de la ley que establece el artículo $117.1 \mathrm{CE} " 29$.

En segundo lugar, porque de un acto ilegal no pueden derivarse derechos que perjudiquen a un tercero, en este caso, el INSS, obligado a pagar la prestación, y porque todo ello se produce con un claro fraude de ley, ya que el actor pudo simplemente reconocer su paternidad, según lo previsto por el artículo 10.3 de la L. 14/2006 pero prefirió reconocer su actuación previa, y la consecuencia de ello es la nulidad ${ }^{30}$.

A pesar de la contundencia de los argumentos esgrimidos en los votos particulares, lo cierto es que, hasta la fecha, la Sala $4^{\text {a }}$ del Tribunal Supremo se ha mostrado favorable al reconocimiento de la prestación, con lo que consagra, como hemos dicho, la legalización de hecho de la maternidad subrogada, al asimilarla a situaciones que no son análogas (adopción, acogimiento y guarda) y reconocer efectos jurídicos laborales a una situación contraria a Derecho.

La situación de legalización de hecho de la maternidad subrogada en ambos supuestos, podría haberse evitado si la LTRHA hubiera incluido a la gestación por subrogación en el catálogo final de infracciones leves, graves o muy graves que aparece al final del texto legal ${ }^{31}$. En definitiva, si hubiera sido mucho más específico el legislador a la hora de prever las consecuencias negativas que todo acto contrario a la ley debe llevar aparejado. El legislador solo ha regulado las consecuencias positivas (el nacimiento de un niño y su relación paternofilial con los causantes) y, salvo la imposibilidad de que la madre genética vea reconocida su filiación natural, no hay ninguna previsión de sanción contenida en la propia Ley en relación a la maternidad subrogada.

Nuestro Código Penal regula la suposición de parto y la alteración de la paternidad, estado o condición del menor en los artículos 220 y 221. Se trata de supuestos en los que se entrega un niño a otra persona obviando las instituciones de guarda, acogimiento o adopción. El art. 221, en concreto, agrava las penas cuando la entrega de un niño tiene

28 STS (25-10-2016) p. 18.

29 Voto particular contra la STS (25-10-2016) que formula el Magistrado D. Luis Fernando de Castro y al que se adhiere D. José Luis Gilolmo López, motivo cuarto, 4, pág. 25.

30 Voto particular contra la STS (25-10-2016) que formula el Magistrado D. José Manuel López García de Serrana al que se adhieren Dña. María Milagros Calvo Ibarluce y D. Jesús Souto Prieto, motivo tercero, 2, pág. 30.

31 GonZÁlez (2017) p. 130. 
lugar a cambio de precio, y hace extensivas estas penas tanto a los intermediarios como a los que reciben el niño, aunque la entrega se haya producido en el extranjero ${ }^{32}$. Esta figura se asemeja mucho a un contrato de gestación por subrogación. Por tanto, solo faltaría su determinación y especificación como infracción administrativa para que esa voluntad legislativa de impedir la gestación por sustitución quedara claramente expuesta, sin resquicio de dudas y sin posibilidad de fraude de ley o legalización de facto ${ }^{33}$.

\section{LA PROPOSICIÓN DE LEY COMO MAL MENOR}

Una de las recomendaciones que los magistrados discordes con el fallo realizan en la Sentencia de 25 de octubre de 2016, es una reforma legislativa pero, advierten, citando la STS de 6 de febrero de 2014, que esta debe ser realizada por el Parlamento "como depositario de la soberanía nacional, con un adecuado debate social y legislativo, sin que el juez pueda ni deba suplirlo" ${ }^{34}$. Haciéndose eco de esta recomendación y ante el encendido debate social suscitado en relación a este asunto, el 8 de septiembre de 2017, como ya dijimos, se presentó al Congreso de los Diputados español la Proposición de Ley reguladora del derecho a la gestación por subrogación (PLDGS), por el Grupo Parlamentario Ciudadanos. En su Exposición de Motivos, se alude expresamente a la legalización de facto que ha supuesto la Instrucción de 5 de octubre de 2010 de la Dirección General de los Registros y del Notariado para justificar su necesidad. Expresamente, reconoce que: "La Instrucción de 5 de octubre ha dejado, en la práctica, sin contenido efectivo la nulidad del contrato de gestación subrogada contenida en la LTRHA, al hacer posible la inscripción en el Registro Civil español del fruto del contrato, con la única condición de que no se haya formalizado en España”. Y añade: "El pragmatismo de la citada Instrucción supone la legalización de facto de la gestación por subrogación en España”35. Por eso, continúa la Exposición de Motivos de la PLDGS, "la mejor solución, la más garantista, es regular, no cerrar los ojos ni prohibir" 36.

En otras palabras, se contempla la regulación de la maternidad subrogada como el mal menor, como la posición intermedia entre los dos extremos representados por quienes

\footnotetext{
32 Art. 221 del Código Penal español: "1. Los que, mediando compensación económica, entreguen a otra persona un hijo, descendiente o cualquier menor aunque no concurra relación de filiación o parentesco, eludiendo los procedimientos legales de la guarda, acogimiento o adopción, con la finalidad de establecer una relación análoga a la de filiación, serán castigados con las penas de prisión de uno a cinco años y de inhabilitación especial para el ejercicio del derecho de la patria potestad, tutela, curatela o guarda por tiempo de cuatro a 10 años.

2. Con la misma pena serán castigados la persona que lo reciba y el intermediario, aunque la entrega del menor se hubiese efectuado en país extranjero".

33 En el mismo sentido se pronuncia Aragón (2017) p. 3.

34 Voto particular contra la STS (25-10-2016) que formula el Magistrado D. Luis Fernando De CASTRO y al que se adhiere D. José Luis Gilolmo López, motivo cuarto, 4, pág. 25.

35 Exposición de Motivos, III, pp. 2 y 3 de la PLDGS.

36 Son muchos los autores se posicionan en el mismo sentido que esta proposición de Ley, a favor de la regulación de la maternidad subrogada gratuita o altruista. Ver, por ejemplo, Vela (2017) p. 17; MarTín, p. 16. Disponible en http://www.fundacionforo.com/pdfs/maternidadsubrogada.pdf. Fecha de consulta: 31 de agosto de 2017 o Vilar (2014) p. 927.
} 
están a favor de la maternidad subrogada, sea del tipo que sea, y los que, en todo caso, se oponen a ella ${ }^{37}$.

La PLDGS aprobada reconoce tan solo la maternidad subrogada gratuita, altruista o solidaria, pero admite la posibilidad de cierta compensación económica por los inconvenientes causados. A pesar de ello, garantiza que en ningún caso pueda haber un lucro en la madre gestante como consecuencia de este servicio ya que incluye, entre las infracciones muy graves, "el pago de cualquier cantidad dineraria o en especie" ${ }^{38}$. Las infracciones graves, según el art. 25.1, pueden llevar aparejadas sanciones que oscilan entre los diez mil y el millón de euros de multa, siendo responsables de ellas los que cometieran la infracción. Si se trata de varias personas, todas ellas responderán de manera solidaria, según el art. 26.

Además, establece una serie de requisitos que deben cumplir las madres gestantes: deben ser mayores de 25 años y menores de lo que se establezca reglamentariamente según las condiciones físico-psíquicas idóneas para un embarazo con éxito; deben haber dado a luz con anterioridad al menos un hijo sano; no pueden aportar material genético propio ni pueden haber gestado para otro anteriormente; deben tener un buen estado de salud general y disponer de una situación socio económica y familiar adecuadas para afrontar esta situación, por citar algunos ${ }^{39}$. Es difícil pensar que haya un gran número de mujeres que, además de desear gestar para otros, puedan llegar a cumplir tantos requisitos y, por otra parte, sorprende su contraste o comparación con los requeridos a los padres comitentes.

En este sentido, el artículo 8 de la PLDGS solo exige que hayan agotado o que sean incompatibles con otras técnicas de reproducción humana asistida, además de tener plena capacidad jurídica, entre 25 y 45 años y nacionalidad o residencia legal en España. Como puede observarse, no se trata de requisitos especialmente difíciles de cumplir ni que garanticen en ningún caso la idoneidad de los padres comitentes para ejercer como tales. Tan solo la última de las exigencias del art. 8.2 de la PLDGS se refiere a este hecho, pero se expresa en unos términos tan vagos que no se entiende de qué manera podrá acreditarse tal requisito. Expresamente determina: "Acreditar que cuenta con la capacidad, aptitud y motivación adecuadas para ejercer la responsabilidad parental asociada a la familia que pretende constituir” ${ }^{40}$. Además, estas endebles exigencias se empequeñecen aún más cuando la PLDGS permite que dichos requisitos sean cumplidos por uno solo de los padres comi-

37 La gestación por sustitución permite muchas variantes que han sido clasificadas por el profesor BELLVET (2015) pp. 24-27. Estas variantes han dado lugar a distintas posturas frente a ellas: "Como siempre sucede ante la aparición de novedades biotecnobiológicas fuertemente controvertidas, se identifican de inmediato tres tipos de posiciones: la 'tecno-entusiasta', que destaca las nuevas posibilidades de satisfacer la maternidad/paternidad que ofrece esta biotecnología y aboga por la liberalización y la autorregulación; la 'prudente', que alerta acerca de los problemas y riesgos que entraña pero confía en la posibilidad de establecer una adecuada regulación para garantizar su buen uso, y la 'tecno-desconfiada', que entiende que estas intervenciones suponen atentados directos contra bienes fundamentales de las personas o de la sociedad y que, en consecuencia, deberían ser prohibidas con carácter general”. BeLLVET (2015) p. 22.

38 Artículo 24, 2, c) 8a de la PLDGS.

39 Artículo 7 de la PLDGS.

40 Artículo 8. 2 de la PLDGS: "El progenitor subrogante deberá cumplir los siguientes requisitos: a) Plena capacidad jurídica y de obrar. b) Ser mayor de 25 años y menor de 45 años. c) Tener la nacionalidad española o residencia legal en España. d) Acreditar que cuenta con la capacidad, aptitud y motivación adecuadas para ejercer la responsabilidad parental asociada a la familia que pretende constituir". 
tentes ya que, si ambos están casados o "unidos por una relación equivalente reconocida por la Ley” ${ }^{41}$, basta que uno solo reúna estas condiciones para que sea lícito el convenio de gestación por subrogación.

Otros aspectos a destacar son la limitación del número máximo de embriones a transferir en cada ciclo reproductivo, y la prohibición de que exista vínculo de consanguinidad (artículo 4.3) o cualquier relación de subordinación económica entre las partes intervinientes (artículo 9.6). Al respecto, llama poderosamente la atención la contradicción que refleja esta prohibición de parentesco por consanguinidad entre la madre gestante y la madre comitente, con el espíritu altruista que refleja la Proposición de Ley en su Exposición de Motivos y que dice ser inspirador de la regulación que nos ofrece ¿Qué puede haber más altruista que una madre consienta en gestar para su hija o hijo?

Por último, se prevé la constitución de un Registro Nacional de Gestación por Subrogación en el que deberán inscribirse las madres gestantes (artículos 15 y 16). Esta inscripción deberá ser renovada anualmente, aportando un certificado expedido por centros autorizados en el que conste la idoneidad de la madre gestante, es decir, que cumple con los requisitos ya expuestos.

A pesar de los intentos de esta PLDGS por salvaguardar la dignidad y la libertad de las partes intervinientes (la gratuidad y la ausencia de vínculo entre las partes son significativos en este sentido), es llamativo que este intento de regular la gestación por sustitución se haya convertido en un punto de encuentro entre posiciones ideológicas tradicionalmente enfrentadas.

En efecto, tanto para el llamado postfeminismo de género, como para el feminismo de la complementariedad (también conocido como feminismo de la diferencia o de la corresponsabilidad $)^{42}$, la regulación de la gestación por subrogación supone una mercantilización de la mujer y, por tanto, un grave atentado contra su dignidad. No obstante, cuando observamos más de cerca los planteamientos de unos y otros, este inicial encuentro se desvanece. En otras palabras, vuelve a hacerse realidad aquella famosa anécdota referida por Jacques Maritain: "estamos todos de acuerdo en esto con tal de que no se nos pregunte por qué ${ }^{\prime \prime 3}$. El desencuentro dentro del encuentro se evidencia tanto por los presupuestos filosóficos de los que parten uno y otro como, sobre todo, en la consideración del hijo, del resultado de la gestación por sustitución, que prácticamente desaparece, o no es tenido en cuenta hasta que nace, en los discursos del feminismo radical (como ha señalado en alguna ocasión la Prof. Garibo ${ }^{44}$ ), mientras que es un argumento muy importante y sólido en con-

\footnotetext{
41 Artículo 8.3 de la PLDGS.

42 Para profundizar en esta tipología, ver, por ejemplo, además de APARISI (2012) pp. 357 a 384 y APARISI (2009) pp. 1696-193, Novoa (2012) pp. 337-356.

43 Literalmente, cuenta Maritain: "Durante una de las reuniones de la Comisión nacional francesa de la UNESCO en que se discutía sobre los Derechos del Hombre, alguien manifestó su extrañeza al ver que ciertos defensores de ideologías violentamente opuestas se habían puesto de acuerdo para redactar una lista de derechos. "Claro -replicaron ellos- estamos de acuerdo en esos derechos a condición de que no se nos pregunte por qué". Es con el "por qué” con lo que la discusión comienza”. Maritain (1983) p. 94.

44 Ver, por ejemplo, Garibo (2017) pp. 245-259.
} 
tra de esta técnica de reproducción asistida en los otros discursos. Por razones de espacio, voy a centrarme solo en el punto de encuentro.

\section{LA MATERNIDAD SUBROGADA COMO PUNTO DE ENCUENTRO ENTRE POSICIONES IDEOLÓGICAS DISTINTAS}

El feminismo no es un movimiento unívoco, sino que, dentro de él, pueden encontrarse distintas variantes. En este sentido, el postfeminismo de género supone una radicalización del llamado feminismo de la igualdad o primer feminismo ${ }^{45}$. Este primer feminismo supuso un notable avance respecto a la defensa de la igualdad entre hombres y mujeres pero, al mismo tiempo, diluyó la diferencia entre ambos, porque, precisamente para luchar contra la subordinación patriarcal, en su afán por igualar la mujer al varón, terminó convirtiéndola en una especie de hombre encerrada en un cuerpo molesto, esclava de procesos biológicos cuyo control se le escapan y que tiene que asistir pasiva, inerme, a la subordinación de su individualidad por la pervivencia de la especie.

El conflicto entre especie e individuo que afecta a la mujer se observa claramente en este fragmento de El Segundo sexo, de Simone de Beauvoir, una de las máximas exponentes de este feminismo: "[...] la individualidad de la hembra, por el contrario, es combatida por el interés de la especie; aparece como poseída por potencias extrañas: enajenada. Por ello, cuando la individualidad de los organismos se afirma más, la oposición de los sexos no se atenúa: todo lo contrario. El macho encuentra caminos cada vez más diversos para utilizar las fuerzas de que se ha adueñado; la hembra siente cada vez más su esclavización; el conflicto entre sus intereses propios y el de las fuerzas generadoras que la habitan se exaspera" ${ }^{36}$.

El postfeminismo de género lleva la igualdad entre sexos hasta el extremo, como hemos dicho, cuando incorpora en estos presupuestos filosóficos la diferenciación entre sexo y género. El primero se considera un hecho biológico y, por lo tanto, dado por la naturaleza, mientras que el segundo se considera como algo construido y dependiente, en última instancia, de la voluntad individual. En este sentido, parte de una visión dualista del ser humano, que le lleva a entender que cualquier referencia a un "orden natural” debe ser rechazada, mientras que reafirman la autodeterminación individual que debe incluir la identidad sexual, sin que esta pueda quedar limitada o determinada por la genética o la biología: "el postfeminismo de género [...] entiende que las desigualdades que padecen las mujeres, traducidas en términos de subordinación, solo desaparecerán en la medida en que ya no se hable de mujeres y de varones, sino de seres indiferenciados que, sin tener en cuenta los aspectos biológicos, adopten en su vida el rol que libremente deseen desempeñar" ${ }^{37}$.

Pero esta autodeterminación individual no alcanza a la gestación por subrogación porque, en el contexto del postfeminismo de género, la maternidad subrogada, entronca directamente con la tradición contractualista de la Modernidad y consagra el modelo de relación género-sexo patriarcal o de subordinación de la mujer al hombre.

\footnotetext{
45 Ver, por ejemplo, Aparisi (2016) p. 7.

46 Beauvoir (1969) p. 11.

47 Ver Aparisi (2016) p. 8 y Cabrera (2016) pp. 6-7.
} 
Efectivamente, el contrato social original consagrado por las teorías políticas modernas de los siglos XVII y XVIII, propició la superación del Antiguo Régimen y la formación de los nuevos sistemas políticos que culminarían en el Estado liberal, gracias a la ficción del pacto unánime entre individuos libres en un estado de naturaleza. Pero la caracterización de este individuo, que libremente pacta con sus congéneres para preservar su libertad e igualdad originarias, es falsamente neutral en lo que al sexo se refiere. Cuando el individuo se constituye en ciudadano a través del pacto social, se excluye a las mujeres de ese contrato. No son, por ello, ciudadanas ni sujetos de derecho, no pueden participar en la vida pública ni en la toma de decisiones políticas ${ }^{48}$.

Una de las pioneras en la relectura de la Modernidad desde una perspectiva de género, ha sido la británica Carole Pateman. Para esta pensadora, el contrato social original es un contrato sexual a través del cual el hombre asegura su derecho sobre la mujer gracias al derecho civil patriarcal ${ }^{49}$. De este modo, para esta pensadora y para las que han seguido su estela, la prostitución y la gestación por subrogación son los dos ejemplos más claros de cómo el patriarcado clásico sigue perviviendo en la actualidad. En palabras de Alicia H. Puleo: “[...] la prostitución y la maternidad subrogada serían dos casos en los que la función de ocultamiento de la subordinación estructural de las mujeres sería más clara. Al entenderlos como contratos legítimos de trabajo, se niega la relevancia de la identidad encarnada de las personas que contratan cuando, en realidad, esta es determinante" ${ }^{50}$. Es decir, tanto en la maternidad subrogada como en la prostitución se utiliza a la mujer precisamente en cuanto que mujer, no en cuanto individuo.

Conviene recordar que todas las técnicas de reproducción humana, desde las más simples (como la inseminación artificial) hasta las más complejas (como una clonación, por ejemplo), dependen de un cuerpo femenino para su éxito. Por ello, la futura regulación de la gestación por subrogación en España y su posible conversión en "derecho", supondría para este feminismo "[...] otro medio a través del cual se asegura la subordinación patriarcal" 51 . Es decir, provocaría, desde esta perspectiva, un retroceso respecto a la posición jurídica que las mujeres ya han conseguido en sociedad después de una larga lucha. Para estas autoras, la regulación de la maternidad subrogada supone una simple transformación del patriarcado clásico, no su eliminación, en lo que Alicia H. Puleo ha denominado "patriarcado del consentimiento" 52 , Ana de Miguel, "neoliberalismo sexual" 53 o Laura Nuño,

\footnotetext{
48 Esta exclusión de la vida política llega a su expresión más depurada en KanT: "El muchacho empleado en casa de un comerciante o fabricante, el sirviente que no está al servicio del Estado, el pupilo (naturaliter, vel civiliter); todas las mujeres, y en general cualquiera que se encuentra compelido a proveer a su existencia, no por medio de una dirección personal sino según las órdenes de otro (excepto del Estado), carece de personalidad civil y su existencia no es en manera alguna más que un accesorio de la de otro”. KANT (1978) p. 24.

49 Pateman (1995) p. 295.

50 Puleo (2017) p. 177.

51 Pateman (1995) p. 295

52 Puleo (1995) pp. 21-54 y Puleo (2017) p. 176.

53 De Miguel (2015). En esta obra, la autora no aborda directamente la cuestión de la gestación por sustitución, pero sus argumentos en defensa de la mujer y en contra de su utilización sexual a través, por ejemplo, de la prostitución, son en mi opinión, perfectamente extrapolables a la maternidad subrogada. La idea principal
} 
"neoliberalismo reproductivo" 54 . Son distintas versiones de una misma idea de la que, precisamente, se hace eco esta Proposición de Ley: la aceptación libre de esta situación supone la garantía de juridicidad y la salvaguarda de la dignidad de las partes. Sigue siendo, pues, válida la ficción del contrato social original, al consagrar "que las relaciones contractuales son el paradigma de las relaciones libres" $"$.

El feminismo de la complementariedad, por su parte, comparte con los anteriores feminismos la lucha contra la subordinación patriarcal de la mujer. Sin embargo, lo hace desde otros presupuestos, en concreto, desde el presupuesto de la igualdad ontológica del hombre y de la mujer. Es decir, entiende que el hombre y la mujer en cuanto que personas, comparten la misma naturaleza y, por tanto, la misma dignidad y los mismos derechos. Pero, al mismo tiempo, esta igualdad no es incompatible con la diferencia que existe entre hombres y mujeres; diferencias que se afirman a nivel genético, biológico, hormonal e, incluso, psicológico. El gran reto de este feminismo de la complementariedad consiste, pues, en afirmar las diferencias existentes entre ambos sexos sin que estas se constituyan en causa alguna de discriminación ${ }^{56}$. Desde estos presupuestos, la regulación de la gestación por sustitución en España, supone un grave atentado contra la dignidad de la mujer gestante y del hijo nacido como consecuencia de esta técnica de reproducción asistida, ya que los sitúa en un contexto mercantilista, en una situación de vulnerabilidad en la que, como veremos a continuación, sus elementales derechos no quedan garantizados ${ }^{57}$.

Precisamente aquí radica el punto de encuentro entre los feminismos ideológicamente distintos que hemos señalado antes. Tanto en el postfeminismo de género como en el feminismo de la complementariedad, se señala el consentimiento de la madre gestante como un consentimiento que no justifica, es decir, que no hace necesariamente justa o legítima, la decisión que sostiene. Por el contrario, los partidarios de la regulación de gestación por sustitución defienden que se trata de un contrato legítimo, al estar realizado por adultos responsables y libres; se defiende la inocuidad de esta técnica de reproducción asistida siempre que se garantice precisamente el libre consentimiento de las partes afectadas. Parece, por tanto, que de nuevo, la autonomía moral se erige en el fundamento último de lo jurídi$\mathrm{co}^{58}$. El postfeminismo de género y el feminismo de la complementariedad entienden que los contratos de gestación por sustitución violentan gravemente la dignidad de la mujer, al convertir lo más específico de su ser, la posibilidad de alumbrar a otro, en un objeto de transacción contractual. Por el contrario, sus defensores entienden que la dignidad queda salvaguardada en el momento en que queda afectada por una decisión libre.

que defiende durante todo el libro es que el consentimiento libre no existe en las mujeres y no es más que un recurso para legitimar y perpetuar las situaciones de subordinación al patriarcado.

54 Nuño (2016) p. 686.

55 Agra (1995) pp. XII-XIII. En el mismo sentido, aunque desde una posición filosófica distinta, AlBERT (2017) pp. 178 y ss. y GONZÁlez (2017) pp. 121 y ss.

56 "Para sostener sus aseveraciones, este modelo busca apoyo en la realidad y, primariamente, en los datos que nos aportan las ciencias experimentales y culturales. Ello requiere, inevitablemente, de un enfoque interdisciplinar”. APARISI (2016) p. 3.

57 LÓpez y APARISI (2012) p. 266

58 Cabrera (2016) pp. 9-10 
En mi opinión, la ideología que subyace en la PLDGS es claramente liberal. La Proposición de Ley se rinde a los intereses del liberalismo y del individualismo radical, olvidando así que la Historia ha demostrado, en más de una ocasión, lo desacertado de este planteamiento y los graves perjuicios de este individualismo exacerbado ${ }^{59}$. Parte del llamado "mito de la libre elección" porque entiende que, como las mujeres ya somos libres, estamos en condiciones de igualdad para elegir ${ }^{60}$. Y podemos elegir libremente qué hacer con nuestros cuerpos, sin que eso lesione o afecte de alguna manera a nuestra dignidad ${ }^{61}$. Por tanto, siguen siendo válidos aquí los argumentos de la Modernidad y del contrato social: en la medida en que las mujeres deciden libremente, todas las consecuencias de esas decisiones quedan justificadas. Pero ¿̇realmente esta Proposición de Ley está garantizando la libertad de decisión de las madres gestantes? Creo que la respuesta debe ser negativa, por dos razones:

En primer lugar, como certeramente ha señalado Marta Albert, por el hecho de que no haya sido impulsada por movimientos colectivos de madres que deseen prestarse para gestar los hijos de otros, sino todo lo contrario: ha sido impulsada por asociaciones de padres que desean contratar a una mujer que geste para ellos ${ }^{62}$. En concreto, han sido dos las asociaciones de ciudadanos que, en España, han impulsado esta Proposición de Ley: la Asociación por la Gestación Subrogada en España (AGSE), en colaboración con la Asociación Son Nuestros Hijos, y el Grupo de Ética y Buena Práctica Clínica de la Sociedad Española de Fertilidad $(\mathrm{SEF})^{63}$. Cada colectivo publicó unas propuestas de regulación de las que la PLDGS presentada por Ciudadanos se hace eco en casi su totalidad y, en la mayoría de las ocasiones, con las mismas palabras ${ }^{64}$. Por tanto, lo que pretende proteger esta Proposición

\footnotetext{
59 Megías (2007) pp. 154-155.

60 “[...] desde posiciones supuestamente progresistas se mantiene que las mujeres ya pueden elegir también ser putas, puesto que ya hay igualdad. Esta defensa de la libertad de elección de las mujeres se ha convertido en un elemento muy importante de la desvirtuación del discurso feminista. Se apela a la libre elección como si esta fuera el fundamento del feminismo, y se resta valor al análisis de una estructura social generalizada y patriarcal que actúa determinando de forma coactiva las elecciones de las personas”. De Miguel (2015) p. 339.

${ }^{61}$ En puridad, la referencia a la dignidad en este contexto podría ser más un punto de desencuentro que de encuentro porque el concepto de dignidad del que parte, el feminismo de la igualdad o el postfeminismo de género, y el feminismo de la complementariedad o de la diferencia, difieren. Para el feminismo de la complementariedad, la dignidad, como hemos dicho antes, hace referencia a un dato ontológico, como es el propio término persona, del que se predica. Así, no admiten distinción alguna entre personas y seres humanos. Todos los seres humanos, son personas y poseen dignidad, con todos los derechos que a ella le son inherentes. La dignidad no admite grados, como no los admite el propio término persona, por lo que se mantiene constante desde el primer momento de la existencia humana hasta el último. Por eso, por ejemplo, el aborto, que el feminismo de la igualdad defiende como una manifestación de la autonomía reproductiva de las mujeres es, desde esta posición, injustificable. Para mayor abundamiento sobre el concepto de dignidad ontológica, puede consultarse: CABRERA (2017) pp. 115 y ss., Aparisi (2014), Megías (2005) p. 250, Hervada (1991) p. 357 o Spaemann (1989) pp. 50 y ss.

62 Albert (2017) p. 179.

63 Bellver (2017) p. 231.

64 El texto de la Proposición de ley de gestación subrogada de la Asociación por la Gestación Subrogada en España está disponible en http://xn--gestacionsubrogadaenespaa-woc.es/images/PDF/Proposicion_de\%20ley.pdf. Fecha de consulta: 26 de marzo de 2018. La Propuesta de bases generales para la regulación en España de la gestación por sustitución del grupo Ética y Buena Práctica Clínica de la Sociedad Española de Fertilidad, puede consultarse en http://www.sefertilidad.net/docs/grupos/etica/propuestaBases.pdf. Fecha de consulta: 26 de
} 
de Ley no es un pretendido derecho de las madres de gestar para otros, sino el legítimo (pero dudosamente jurídico) deseo de los padres comitentes de tener un hijo a toda costa.

En segundo lugar, especialmente revelador de la ideología que impregna esta Proposición de Ley es el tratamiento que otorga al consentimiento informado de la madre gestante.

El art. 9.2 de la PLDGS, en su apartado b), establece que el contenido mínimo del contrato de gestación por subrogación, tiene que recoger el "consentimiento informado, libre, expreso e irrevocable de las partes intervinientes". A mi modo de ver, al constituirlo como irrevocable, está restringiendo gravemente la autonomía personal de la madre gestante ${ }^{65}$.

Precisamente, el pasado 24 de abril de 2018, el Tribunal Constitucional portugués fallaba contra varios artículos de la Lei No 32/2006, de técnicas de reproducción médicamente asistida. Aunque el Tribunal considera que la gestación por sustitución no viola la dignidad de la gestante ni la del niño así concebido ${ }^{66}$, sí hay puntos que son contrarios a la Constitución portuguesa. Uno de ellos es, en concreto, el tratamiento que el artículo 8.8 (en remisión al artículo 14.5 de la misma Ley) hace del consentimiento, porque: "no admite la revocación del consentimiento de la gestante de sustitución hasta la entrega del niño a los beneficiarios". Por tanto, se declara su inconstitucionalidad "por violación de su derecho al desarrollo de la personalidad, interpretado de acuerdo con el principio de dignidad de la persona humana, y con el derecho a constituir una familia" ${ }^{67}$.

Esto que ve tan claro el TC portugués no es tenido en cuenta, sin embargo, por el legislador español que declara la irrevocabilidad del consentimiento de la madre gestante desde el primer momento en que decide aceptar el convenio de gestación. Por tanto, en el caso de que consiga ser aprobada por las Cortes Generales, estos argumentos podrían extrapolarse perfectamente a la PLDGS. Máxime si se tiene en cuenta que, en España, toda la normativa que informa la asistencia sanitaria, la investigación biomédica en personas o la donación de órganos, establece la posibilidad de revocar el consentimiento, libremente y sin incurrir en indemnización o sanción alguna. El paciente tiene, en el caso de las donaciones, un plazo de veinticuatro horas desde que se autoriza la donación hasta que se produce la intervención quirúrgica, para ejercer este derecho, sin que deba someterse a ningún tipo de formalidad en la comunicación de su revocación ${ }^{68}$. Incluso en la adopción, aunque

marzo de 2018. Las escasas diferencias entre la Proposición de Ley del grupo Ciudadanos y estos textos afectan, sobre todo, a la edad mínima de la mujer para ofrecerse como gestante, al vínculo entre esta y los padres comitentes, al número de embriones transferidos a la madre gestante en cada ciclo reproductivo y a la posibilidad de emplear esta técnica por persona soltera.

65 “(...) a nuestro juicio, sería una contradicción querer sustentar la gestación por sustitución en la autonomía, en la libertad y, al mismo tiempo, defender la irrevocabilidad del consentimiento, la cual conlleva una renuncia a la autonomía, a la libertad”. GonzÁlez Moreno (2017) p. 215.

66 Esta opinión es rechazada en las "declaraciones de voto" posteriores firmadas por DÑa. Maria de Fátima MataMouros, Dña. Maria José Rangel de Mesquita, D. José António Teles Pereira, D. Joāo Pedro Caupers.

${ }^{67}$ Decisão b), pág. 1954: "Declarar a inconstitucionalidade, com força obrigatória geral, da norma do n. 8 do artigo $8 .^{\circ}$ da Lei n. $.^{\circ} 32 / 2006$, de 26 de julho, em conjugação com o n. ${ }^{\circ} 5$ do artigo $14 .^{\circ}$ da mesma Lei, na parte em que não admite a revogação do consentimento da gestante de substituição até à entrega da criança aos beneficiários, por violação do seu direito ao desenvolvimento da personalidade, interpretado de acordo com o princípio da dignidade da pessoa humana, e do direito de constituir familia".

68 Artículo 8.6 del Real Decreto 1723/2012, de 28 de diciembre, por el que se regulan las actividades de obtención, utilización clínica y coordinación territorial de los órganos humanos destinados al trasplante y se esta- 
se trata de un supuesto que, a mi juicio, no admite comparación con la maternidad subrogada $^{69}$, el Código Civil exige que el necesario asentimiento de la madre no se produzca hasta que hayan transcurrido seis semanas después del parto ${ }^{70}$.

Al establecer el carácter irrevocable del consentimiento, la PLDGS revela que ya no son los principios de la ética los que la informan, sino los principios del mercado, porque se trata de dar satisfacción y de proteger los deseos de los padres comitentes de tener un hijo a toda costa. Solo desde esta perspectiva puede entenderse ese cambio de criterio sobre el carácter irrevocable del consentimiento en una técnica que no solo va a afectar puntualmente a la salud de la madre gestante, sino que la va a condicionar durante los nueve meses que dure el embarazo e, incluso, toda su vida ${ }^{71}$. Lógicamente, la posibilidad de revocar el consentimiento estaría poniendo en peligro las expectativas de los padres intencionales ya que, si se admitiera la posibilidad de que la madre gestante revocara su consentimiento, el niño que se está gestando, o bien no llegaría a nacer, o no sería entregado a sus padres biológicos y, en ambos casos, el resultado es el mismo desde el punto de vista de los padres comitentes: no verían satisfecho su deseo de ser padres.

Sin embargo, la PLDGS sí deja a salvo el consentimiento de la madre gestante, no ya para entregar o no el niño una vez nacido, sino para ejercer su derecho a la interrupción voluntaria del embarazo, es decir, para impedir que ese niño nazca, al amparo de la L.O. $2 / 2010^{72}$. Resulta bastante desconcertante, como poco, esta peculiar manera de regular la revocación del consentimiento informado que solo es tenido en cuenta cuando, al ejercerla, se evita la aparición del objeto de la relación entre los padres comitentes y la madre gestante. Solo se entiende esta posibilidad desde una posición mercantilista extrema en la que el niño se cosifica: Si la madre aborta, es cierto que tampoco se pueden cumplir las expectativas de los padres comitentes pero, al no haber "producto", tampoco habrá disputas entre las partes sobre la paternidad, maternidad, filiación y todas las consecuencias jurídicas que derivan de estas instituciones. El problema se zanja simplemente haciendo a la madre gestante responsable económicamente por los daños y perjuicios ocasionados. Son los principios propios del derecho contractual ${ }^{73}$.

Pero hay algo aún más perverso en la regulación de la maternidad subrogada que propone Ciudadanos, porque al establecer la irrevocabilidad del consentimiento de la madre gestante, invierte los términos clásicos y racionales que impregnan el Derecho de con-

\footnotetext{
blecen requisitos de calidad y seguridad.

69 La adopción es una institución dirigida a procurar padres a quien no los tiene, mientras que la maternidad subrogada es justo lo contrario. De ahí que, en el primer caso, prime el interés del menor y, en el segundo, el de los padres comitentes.

70 Artículo $177.12^{\circ}$ del Código Civil.

71 Existen evidencias científicas sobre los cambios que el embarazo provoca en el cuerpo de la madre, sobre todo en su cerebro. Ver, por ejemplo, el Informe del Comité de Bioética de España sobre los aspectos éticos y jurídicos de la maternidad subrogada, de 16 de mayo de 2017, p. 13; López Moratalla (2018) pp. 49-83; López Moratalla (2009) pp. 303-315; Jouve (2018) p. 36 y Jouve (2017) p. 155.

72 Artículo 6.2 de la PLDGS

73 Realmente, la Proposición de Ley no especifica las consecuencias que deberán asumir las madres que decidan abortar en contra de los deseos de los padres comitentes, tan solo se limita a reconocerles tal posibilidad. En todo caso, entendemos que se trata de una consecuencia lógica y coherente con la irrevocabilidad del consentimiento.
} 
tratos. Cuando el Derecho interviene para regular y poner límites a la autonomía de la voluntad, lo hace para proteger siempre los intereses de la parte más débil. Toda la regulación laboral, por ejemplo, se asienta sobre este principio y, por ello, el legislador establece un mínimo de condiciones laborales (en horarios, salarios, etc.) por debajo de las cuales el contrato laboral no se ajusta a la legalidad vigente. Así se garantiza que, por muy precarias que sean las condiciones de vida de un trabajador, este no vaya a aceptar condiciones laborales que puedan ir en detrimento de su dignidad humana. En el caso de la pretendida regulación española de la gestación por sustitución, el legislador defiende y protege los intereses de la parte más fuerte de la relación: los intereses de los padres comitentes, que son los que $\operatorname{pagan}^{74}$. Y, de este modo (un modo taimado y sutil) la madre gestante pasa de ser sujeto del derecho a gestar para otros, a ser sujeto de un sinfín de obligaciones recogidas todas ellas en el convenio (contrato) gestacional ${ }^{75}$. Una vez que lo acepta, la imposibilidad de arrepentirse sin tener que asumir coste alguno por ello, la sitúa en una posición de explotación que es contraria a los principios básicos del Derecho.

Si la finalidad de maternidad subrogada es un acto de generosidad y solidaridad, como dice la Exposición de Motivos de esta PLDGS, por la que una mujer ayuda a otros a satisfacer su deseo de ser padres, lo razonable hubiera sido admitir la posibilidad de una revocación del consentimiento sin penalización alguna. No puede existir un consentimiento libre sin que se admita la posibilidad de revocación sin compensación económica. Si esto sucede, los sentimientos altruistas y solidarios se sustituyen por los intereses de parte clásicos de las transacciones mercantiles, donde se imponen precisamente los de la parte con más fuerza para negociar. La regulación de esta técnica de reproducción, por tanto, no es más una nueva forma de explotación de la mujer, disfrazada de falsa generosidad y altruismo ${ }^{76}$. Es otra forma de mercantilización de la mujer, al igual que la prostitución, que intenta legitimarse desde el ejercicio de una mal entendida libertad individual. Y en esta consideración están de acuerdo las dos posiciones feministas antagónicas a las que nos hemos referido antes.

Por otra parte, los exigentes requisitos que la madre gestante debe cumplir según el art. 7 de la PLDGS ${ }^{77}$, harán, en la práctica, disminuir las posibilidades reales de encontrar un vientre idóneo. Es decir, es poco probable que con esta regulación se pueda evitar el

74 Para Albert, esto supone un "antijurídico", contrario "al más elemental sentido de la justicia”. AlberT (2018a) p. 129.

75 Albert (2018a) pp. 128-129.

76 "El altruismo es una trampa, un señuelo que pretende ocultar otras consecuencias de la subrogación uterina. Detrás del altruismo hay, en primer lugar, la satisfacción del interés de aquellos que sí se lucran con este negocio: los agentes intermediarios, y la tranquilidad de las conciencias de sus clientes. Nadie como ellos precisa del altruismo y de la solidaridad, porque son los argumentos que legitiman moralmente su negocio". AlBERT (2018a) p. 138.

77 Lo reproduzco: "Artículo 7. Requisitos de la mujer gestante.

1. La mujer gestante por subrogación deberá cumplir los siguientes requisitos:

a) Ser mayor de 25 y menor de la edad que reglamentariamente se fije en función de las condiciones psicofísicas que se consideren adecuadas para la gestación con éxito.

b) Plena capacidad jurídica y de obrar.

c) Tener buen estado de salud psicofísica, conforme a lo dispuesto en el artículo 5.6 de la Ley 14/2006, de 26 de mayo, sobre técnicas de reproducción humana asistida, respecto de las exigencias fijadas a los donantes. 
llamado turismo reproductivo. Los padres comitentes con nivel económico que no encuentren una madre gestante idónea en España seguirán acudiendo al extranjero, donde los controles son menores y los procesos más ágiles y menos garantistas para la parte más débil (la madre gestante). Dicho de otro modo, el que se regule en España la maternidad subrogada gratuita no impedirá que se pueda seguir acudiendo al extranjero para obtener, a cambio de precio y por fraude de ley, lo que la legislación nacional les impide ${ }^{78}$.

Ya hemos asistido a este proceso en muchas ocasiones. Primero se regulará la maternidad subrogada gratuita como ejemplo de altruismo y generosidad. Luego, ante el desequilibrio entre la oferta de madres gestantes y la demanda de padres comitentes ${ }^{79}$, se exigirá la regulación de la maternidad subrogada comercial y se producirá la consiguiente profesionalización de las madres gestantes ${ }^{80}$. Por último, las posibilidades de las Técnicas de Fecundación In vitro (FIV o TFIV) harán nacer la necesidad de admitir y regular las relaciones pluriparentales basadas en una filiación volitiva y, en lógica consecuencia, se exigirá la inscripción de dicha multiparentalidad en el Registro Civil ${ }^{81}$ : si en la producción de un

d) Tener buen estado de salud mental y, en particular, no haber sufrido episodios de depresión o desórdenes psíquicos.

e) Haber gestado, al menos, un hijo sano con anterioridad.

f) Disponer de una situación socio-económica, así como familiar, adecuadas para afrontar la gestación en condiciones óptimas de salud, bienestar y seguridad.

g) Poseer la nacionalidad española o residencia legal en España.

h) No tener antecedentes penales.

i) No tener antecedentes de abuso de drogas o alcohol.

j) No haber sido mujer gestante por subrogación en más de una ocasión con anterioridad.

2. La mujer gestante se obliga a mantener, a lo largo de la gestación, el cumplimiento de los requisitos de las letras c), d), f), h) y j).

En caso de cambio o modificación en el cumplimiento de los requisitos, deberá comunicarlo inmediatamente al Registro Nacional de Gestación por Subrogación y a los progenitores subrogantes.

3. La mujer gestante está obligada a someterse, en todo momento, a las evaluaciones psicológicas y médicas, que sean necesarias para garantizar el cumplimiento de los requisitos exigidos. A tal fin, también deberá estar dispuesta a proporcionar todo su historial médico, así como la información económica y personal necesaria para la acreditación de los requisitos enumerados.

4. El examen de la concurrencia de las condiciones y requisitos enumerados en esta Ley se producirá, por los centros públicos habilitados por las Comunidades Autónomas, con ocasión de la inscripción de la mujer en el registro contemplado en esta Ley. Si el resultado del examen es negativo, no podrá inscribirse en el registro, ni acceder, en consecuencia, a la posibilidad de la gestación subrogada.

5. El cumplimiento de los requisitos deberá producirse con la antelación máxima de un mes a la celebración del contrato, según la certificación del Registro Nacional de Gestación por Subrogación emitida al efecto".

78 Puleo (2017) pp. 178 y ss. Desde una posición filosófica distinta, ver también Albert (2018a) p. 143.

79 Albert (2017) pp. 178 y ss., Albert (2018b) y González Carrasco (2017) pp. 121 y ss.

${ }^{80}$ Abogan por ello, por ejemplo, las profesoras de la Universidad de Waikato (Nueva Zelanda), LieZL VAN ZYL Y RUTH WALKER. Ellas proponen, para aquellos países donde esté ya regulada y admitida la gestación por subrogación, la creación de una especie de Agencia o Departamento gubernamental, a través de la cual se garanticen los derechos laborales de las madres gestantes, haciéndolos compatibles con los intereses de los padres intencionales y de los hijos nacidos por esta técnica. Ver Van ZyL y WalKer (2017), VAN ZyL y WalKer (2015) pp. 529-535, y VAN ZyL y WaLKer (2013) pp. 373-381.

${ }^{81}$ Es la propuesta, por ejemplo, LAMm (2012b) pp. 87 y ss. También se apunta en la conclusión final de la "declaración de voto" de D. Fernando Ventura, D. Lino Ribeiro, Dña. Joana Fernandes Costa y Cláudio MonTeiro a la sentencia del Tribunal Constitucional portugués de 24 de abril de 2018: "Todo este conjunto de interrogaciones (...) impone una sustitución del modelo de reconocimiento legal de la parentalidad en favor de 
hijo intervienen más de dos personas ¿por qué impedir que todas ellas, si así lo quieren y lo hacen constar ante el Encargado del Registro Civil, puedan ser consideradas progenitores? Cuantas más personas participen en la educación y crianza del niño, mayor garantía de protección para él. De nuevo, estaremos ante una utilización tendenciosa del argumento del interés primordial del menor.

Es cierto que este argumento, conocido en bioética como la "pendiente resbaladiza" (slippery slope, en inglés), resulta muy difícil de probar. No obstante, algunos autores han demostrado que no se trata de una teoría ilusoria, sino de un fenómeno real, al menos, en el caso de la regulación de la eutanasia en Australia, en el estado de Oregón (EE.UU) y en Holanda $^{82}$. Las consecuencias negativas que se pueden derivar de una regulación de la maternidad subrogada parecen aconsejar, al menos, una actitud prudente respecto a la admisibilidad del mismo. De hecho, en el caso de la India, las consecuencias negativas puestas de relieve por el Informe Surrogacy Motherhood: Ethical or Commercial?, del Centre for Social Research ${ }^{83}$, han motivado la limitación de esta técnica a contratos gratuitos entre nacionales indios, casados entre sí, con algún vínculo de parentesco con la madre gestante. Sin embargo, esto no ha hecho disminuir la demanda de madres gestantes ni el turismo reproductivo. Sencillamente, este se ha trasladado a otros países con una regulación más permisiva, como Ucrania, por ejemplo.

En definitiva, aunque la opción de regular la maternidad subrogada se presente como un mal menor, en el que el consentimiento informado de la madre gestante y la gratuidad del negocio aparezcan como garantes de la juridicidad del mismo, sigue siendo un mal y plantear propuestas malas, sabiendo que son malas pero esperando con ello evitar el triunfo de propuestas aún peores es, como poco, censurable pero, ante todo es completamente ineficaz, porque no evita el mal.

\section{PARA CONCLUIR: UNA PROPUESTA DE MODIFICACIÓN DE LA REGULACIÓN DE LA MATERNIDAD SUBROGADA}

Es cierto que la situación actual de la regulación de la maternidad subrogada necesita una reforma. Pero ¿en qué sentido?

En Europa existen dos modelos de regulación de la gestación por sustitución: el modelo griego y el modelo británico ${ }^{84}$. En el primero, el consentimiento es irrevocable, desde

\footnotetext{
los 'padres intencionales y genéticos', por un modelo judicial de establecimiento de la filiación basado en una valoración casuística -y, por lo tanto, contingente y discutible- de las circunstancias del caso (...)". "Todo este conjunto de interrogaçôes (...) imponha a substituição do modelo de reconhecimento legal da parentalidade a favor dos 'pais intencionais e genéticos' por um modelo judicial de estabelecimento da filiação baseado numa valoração casuistica -e, por isso, contingente e disputável- das circunstâncias do caso, ainda que norteada, neste como em todos os outros conflitos a dirimir no âmbito da jurisdiçāo de menores, pelo superior interesse da criança".

82 Ver, por ejemplo, Vega y Ortega (2007) y Ortega (2003).

83 Disponible en http://www.csrindia.org/about-us/publications/research-studies/109-surrogacy-motherhoodethical-or-commercial. Fecha de consulta: 17 de enero de 2019.

${ }^{84}$ En Derecho comparado, existen cuatro modelos de regulación de la gestación por sustitución: Reino Unido, Grecia, Brasil e India. Ver Albert (2018a) pp. 120-125. Un análisis desde la perspectiva laboral a partir de la Jurisprudencia del Tribunal de Justicia de la Unión Europea puede verse en GuerRero y Ribes (2015) pp. 361-388.
} 
el momento en que se inician los procedimientos de FIV. En el segundo, el niño pertenece a la madre gestante, desde el primer momento del embarazo, hasta el último, y esta dispone de un tiempo para que, una vez haya dado a luz, consienta la cesión del mismo. Los dos modelos son insatisfactorios. El primero, porque, como hemos visto, limita la autonomía de la mujer e incide en su derecho fundamental al desarrollo de su personalidad. El segundo porque genera una grave situación de inseguridad jurídica para los padres comitentes y para el hijo por nacer ${ }^{85}$.

Junto a estos dos modelos de regulación, existe una tercera posibilidad por la que han optado países de nuestro entorno. Me refiero a la posibilidad de reformar la actual regulación para que se persiga, de manera contundente, la realización de estas prácticas en el extranjero. Primeramente, a través de la inclusión de la maternidad subrogada en el listado final de infracciones de la LTRHA, de modo que las sanciones administrativas refuercen la sanción penal contenida en el tipo delictivo de simulación de parto de los artículos 220 y 221 del Código Penal. En segundo lugar, impidiendo la posibilidad de una inscripción de filiación por naturaleza a los padres que, a pesar de la prohibición, acudan al extranjero a comprar ese servicio ${ }^{86}$. Es cierto que, de este modo, no impediremos el turismo gestacional como, por otra parte, tampoco lo hará la PLDGS actual, aunque sí podremos impedir sus efectos. Para ello, es necesario que, al mismo tiempo, se promueva un acuerdo internacional para iniciar una prohibición universal de la maternidad subrogada, al menos en su modalidad onerosa, a fin de evitar la explotación de mujeres en países menos garantistas ${ }^{87}$. En este sentido, la propuesta que aquí se apunta debería seguir los mismos principios de los actuales instrumentos jurídicos internacionales que regulan la donación y trasplantes de órganos. Estos instrumentos (en su mayoría, de carácter voluntario) están inspirados en la necesidad de luchar contra los delitos internacionales de tráfico de órganos que se han visto incrementados como consecuencia de la insuficiente disponibilidad de órganos y el consecuente aumento de las listas de espera ${ }^{88}$.

Los principios que inspiran esta regulación internacional son el "concepto esencial de la dignidad del ser humano y del respeto de sus derechos humanos, lo que implica también la no comercialización del cuerpo humano o de partes del mismo" ${ }^{89}$.

No resulta muy disparatado o forzado entender que, si ya existe un amplio consenso internacional para prohibir la venta o comercialización de algunas partes del cuerpo humano, no pueda lograrse un consenso semejante para impedir la contratación de un vientre

85 García y Herrero (2018) p. 84.

86 Precisamente, este es el modelo actual de Suecia y Alemania.

87 Esta fue una de las recomendaciones del Informe del Comité de Bioética de España, de 19 de mayo de 2017 y también es la propuesta que defienden, entre otros, Albert (2017) p. 192, García y Herrero (2018) p. 87 y González Carrasco (2017) p. 130.

88 Junto al tráfico de órganos, otra consecuencia de la desproporción entre oferta y demanda de órganos es el aumento del turismo de trasplantes que, al igual que el turismo gestacional, se ampara en legislaciones menos garantistas.

89 Pons (2016), p. 34 
para gestar para otros ${ }^{90}$. Si se lograra, las agencias intermediarias que ahora actúan con total impunidad, se verían obligadas a facilitar una información exacta de la prohibición (que actualmente existe) de la gestación por subrogación en España y de la imposibilidad de que esta surta efectos, tanto en la filiación como en las prestaciones por maternidad, por ser contrarias a Derecho.

Y, en cuanto a la modalidad gratuita, solo podríamos llegar a admitir su regulación en tanto que se admitiera la revocabilidad del consentimiento de la madre gestante, tanto durante el embarazo, como en un plazo razonable de tiempo después del parto.

En definitiva, la falacia del consentimiento libre e informado no puede enmascarar la explotación que subyace en la maternidad subrogada, donde la actual propuesta de regulación de la misma únicamente serviría a los intereses de los padres comitentes o intencionales y, sobre todo, a los intereses económicos de las agencias intermediarias, que son las realmente beneficiadas en este asunto. Es posible que, tras la defensa de una mal entendida libertad o autonomía de la voluntad, se esté cediendo a la presión de las agencias intermediarias en su lucha por legitimar su negocio, ya que la prohibición de obtener un lucro con la gestación de un bebé es solo hacia la madre de alquiler, no hacia las agencias que facilitan la selección de las mismas.

Con la propuesta actual de regulación de la maternidad subrogada en España, desde la perspectiva de la mujer gestante, nos situamos ante una terrible paradoja en la que, libremente, la mujer gestante renuncia a su libertad. En definitiva: la libertad se pierde por la libertad.

\section{BIBLIOGRAFÍA CITADA}

Agra, María Xosé (1995): “Introducción”, en Pateman, Carole (ed.), El Contrato sexual (trad. Ma Luisa Femenías, Barcelona, Anthropos) pp. VII-XVI.

Albert, Marta (2016): "Madre no hay más que una, pero de alquiler. Matrimonios homosexuales de varones y gestación por sustitución”, en VV.AA., XX Congreso Internacional Ciencia y Vida "La vida humana y la preservación de la casa común", pp. 1-19. Disponible en http://ulia.org/ficv/wp-content/uploads/2016/08/Marta-Albert.pdf. Fecha de consulta: 10 de abril de 2017.

AlberT, Marta (2017): "La explotación reproductiva de mujeres y el mito de la subrogación altruista: Una mirada global al fenómeno de la gestación por sustitución”, Cuadernos de Bioética, Vol. XXVIII, No 93: pp. 177-198.

90 Junto a numerosas recomendaciones e instrumentos jurídicos de carácter voluntario, existen tres documentos internacionales vinculantes, que abordan el tráfico de órganos, ratificados por España: el Protocolo Facultativo de la Convención sobre los Derechos del Niño, relativo a la venta de niños, la prostitución infantil y la utilización de niños en la pornografía, hecho en Nueva York el 25 de mayo de 2000 (BOE núm. 27, de 31 de diciembre de 2002); el Protocolo para prevenir, reprimir y sancionar la trata de personas, especialmente mujeres y niños, que complementa la Convención de las Naciones Unidas contra la delincuencia organizada transnacional, hecho en Nueva York el 15 de noviembre de 2000 (BOE núm. 296, de 11 de diciembre de 2003) y el Convenio del Consejo de Europa sobre la lucha contra la trata de seres humanos (Convenio No 197 del Consejo de Europa), hecho en Varsovia el 16 de mayo de 2005 y ratificado por España en 2009 (BOE núm. 219, de 10 de septiembre de 2009). 
Albert, Marta (2018a): "La maternidad altruista y la maternidad subrogada...", en Jouve, Nicolás (Coord.) La maternidad subrogada. Qué es y cuáles son sus consecuencias (Madrid, Editorial Sekotia) pp. 114-145.

Albert, Marta (2018b): "Maternidad subrogada. Cinco falacias sobre el 'altruismo' que mercantiliza a madre e hijo", El debate de hoy [Publicación en línea]. Disponible en https:// eldebatedehoy.es/familia/maternidad-subrogada/\#. Fecha de consulta: 6 de junio 2018.

Aparisi, Ángela (2009): "Ideología de género, de la naturaleza a la cultura", Persona y Derecho, No 61: pp. 169-194.

ApARISI, Ángela (2013): “Modelos de relación sexo-género: De la ‘ideología de género’ al modelo de la complementariedad varón-mujer”, Dikaion, Vol. 1, No 2: pp. 357-384.

ApARISI, Ángela (2014): "El principio de la dignidad humana como fundamento de un bioderecho global”. Disponible en https:/www.almudi.org/articulos/8802-el-principio-dela-dignidad-humana-como-fundamento-de-un-bioderecho-global. Fecha de consulta: 14 septiembre 2017.

ApARISI, Ángela (2016): "Modelos de relación sexo-género y Derecho", en ApARISI, Ángela (coord.) Estudios sobre Género y Derecho. Hacia un modelo de género de la igualdad en la diferencia (Cizur menor, Thomson Reuters Aranzadi) 28 páginas.

Aragón, Cristina (2017): "La legalización de facto de la maternidad subrogada. A propósito de los recientes pronunciamientos de la sala de lo social del Tribunal Supremo con respecto a las prestaciones por maternidad", Revista de información laboral, No 4: pp. 1-30.

Atwood, Margaret (1985) The Handmaid's Tale (Canadá, McClelland \& Stewart).

Beauvoir, S. de (1969): El segundo sexo, Tomo I. Los hechos y los mitos (Buenos Aires, Editorial Siglo Veinte).

Bellver, Vicente (2017): “Tomarse en serio la maternidad subrogada altruista”, Cuadernos de Bioética, Vol. XXVIII, No 93: pp. 229-244.

Bellvet, Vicente (2015): “¿Nuevas tecnologías? Viejas explotaciones. El caso de la maternidad subrogada internacional”, SCIO, Revista de Filosofía, No 11: pp. 19-52.

CABrera, Leticia (2016): "El modelo de la complementariedad desde una perspectiva histórico-jurídica”, en APARISI, Ángela (coord.) Estudios sobre Género y Derecho. Hacia un modelo de género de la igualdad en la diferencia (Cizur menor, Thomson Reuters Aranzadi) 21 páginas.

Cabrera, Leticia (2017): “Personas y seres humanos ¿Distinción o identidad?”, Ius et Scientia, No 3: pp. 114-124.

Comité de Bioética de España (2017): "Informe del sobre los aspectos éticos y jurídicos de la maternidad subrogada, de 16 de mayo". Disponible en http://assets.comitedebioetica.es/files/documentacion/es/informe_comite_bioetica_aspectos_eticos_juridicos_maternidad_subrogada.pdf. Fecha de consulta: 15 de febrero de 2018.

De Miguel, Ana (2015): Neoliberalismo sexual: el mito de la libre elección (Madrid, editorial Cátedra).

García, María Paz y Herrero, Margarita (2018): "Maternidad subrogada: dilemas éticos y aproximación a sus respuestas jurídicas", Anales de la Cátedra Francisco Suárez, No 52: pp. 67-89. 
Garibo, Ana Paz (2017): "El interés superior del menor en los supuestos de maternidad subrogada”, Cuadernos de Bioética, Vol. XXVIII, No 93: pp. 245-260.

González Carrasco, María del Carmen (2017): "Gestación por sustitución: ¿regular o prohibir?”, Revista CESCO de Derecho de Consumo, No 22: pp. 117-131.

GonZÁlez Moreno, Juana María (2017): La autonomía reproductiva de las mujeres: los límites del Derecho. Un ensayo filosófico-jurídico (Oviedo, Ediciones Trabe).

Guerrero, Thais y Ribes, Isabel (2015): "La no discriminación por género en la doctrina del Tribunal de Justicia de la Unión Europea”, en Cruz Villalón, Jesús, Garrido PéRez, Eva, Ferradans, Carmen (Coords.), Tutela y promoción de la plena integración de la mujer en el trabajo: Libro homenaje a la profesora Teresa Pérez del Río (Sevilla, Consejo Andaluz de relaciones Laborales) pp. 361-388.

Hervada, Javier (1991): "Los derechos inherentes a la dignidad de la persona humana", Humana Iura, No 1: pp. 345-362.

Jouve, Nicolás (2017): "Perspectivas biomédicas de la maternidad subrogada", Cuadernos de Bioética, Vol. XXVIII, No 93: pp. 153-162.

Jouve, Nicolás (2018): "El significado de la maternidad y de la familia", en Jouve, Nicolás (Coord.) La maternidad subrogada. Qué es y cuáles son sus consecuencias (Madrid, Editorial Sekotia) pp. 10-47.

Kant, Immanuel (1978): Principios metafísicos de la doctrina del derecho (ed. Arnaldo Córdova, México, Universidad Nacional Autónoma de México).

Lamm, Eleonora (2012a): "Gestación por sustitución. Realidad y Derecho", InDret. Revista para el análisis del Derecho, No 3: pp. 1-49.

LAmM, Eleonora (2012b): "La importancia de la voluntad procreacional en la nueva categoría de filiación derivada de las técnicas de reproducción asistida”, Revista de Bioética y Derecho, No 24: pp. 76-91.

López GuZMÁn, José y APARISI, Ángela (2012): “Aproximación a la problemática ética y jurídica de la maternidad subrogada”, Cuadernos de Bioética, Vol. XXIII, No 78: pp. 253-268.

López GuZmán, José (2017): "Dimensión económica de la maternidad subrogada ('habitaciones en alquiler')”, Cuadernos de Bioética, Vol. XXVIII, No 93: pp. 199-218.

López Moratalla, Natalia (2009): “Comunicación materno-fetal en el embarazo”, Cuadernos de Bioética, Vol. XX, No 70: pp. 303-316.

López Moratalla, Natalia (2018): “Mater semper certa est. El vínculo madre-hijo durante la Gestación”, en Jouve, Nicolás (Coord.) La maternidad subrogada. Qué es y cuáles son sus consecuencias (Madrid, Editorial Sekotia) pp. 49-83.

Maritain, Jacques (1983): El hombre y el Estado (trad. Juan Miguel Palacios, Madrid, Ediciones Encuentro).

Martín, Javier (2009): "Maternidad subrogada: una práctica moralmente aceptable. Análisis crítico de las argumentaciones de sus detractores". Disponible: http://www.fundacionforo.com/pdfs/maternidadsubrogada.pdf. Fecha de consulta: 31 de agosto de 2017.

Megías, José Justo (2005): "Dignidad, universalidad y derechos humanos", Anuario de Filosofía del Derecho, No 22: pp. 247-263.

Megías, José Justo (2007): “Cuando las apetencias se convierten en derecho", Persona y Derecho, No 56: pp. 139-156. 
NovoA, Marta Miranda (2012): “Diferencia entre la perspectiva de género y la ideología de género", Dikaion, Vol. 21, No 2: pp. 337-356.

NúNEZ, María (et al.) (2015): "El interés del menor y los supuestos de discriminación en la maternidad subrogada, entre la realidad jurídica y la ficción", Derecho Privado y Constitución, No 29: pp. 227-261.

NuÑo, Laura (2016): "Una nueva cláusula del Contrato Sexual: vientres de alquiler", Isegoría, No 55, 2016: pp. 683-700.

Olavarría, María Eugenia (2002): “De la casa al laboratorio. La teoría del parentesco hoy día”, Alteridades, No 12 (24): pp. 99-116.

Ortega, Ínigo (2003): “La 'pendiente resbaladiza' en la eutanasia: ¿ilusión o realidad?”, Annales Theologici, 17: pp. 77-124.

Pateman, Carole (1995): El Contrato sexual (trad. Ma Luisa Femenías, Barcelona, Anthropos).

Pons, Xavier (2016): "Nuevos desarrollos en la lucha internacional contra el tráfico de órganos humanos: El Convenio de Santiago de Compostela", Revista Electrónica de Estudios Internacionales, 31: pp. 1-36.

Puleo, Alicia H. (1995): "Patriarcado", en Amorós, Celia (dir.), Diez palabras clave sobre Mujer (Estella, Editorial Verbo Divino) pp. 21-54.

Puleo, Alicia H. (2017): "Nuevas formas de desigualdad en un mundo globalizado. El alquiler de úteros como extractivismo", Revista Europea de Derechos Fundamentales, No 29: pp. 165-184.

Romero, Hilarión (1895): Axiomas o principios de legislación universal sacados de Las pandectas, Código e Institutas de Justiniano (Guadalajara, México).

Serrano, José Miguel (2017): "Manipulación del lenguaje, maternidad subrogada y altruismo”, Cuadernos de Bioética, Vol. XXVIII, No 93: pp. 219-228.

SPAEMANN, Robert (1989): Lo natural y lo racional (Madrid, Rialp).

VAn ZyL, Liezl L. y WalKer, Ruth (2013): "Beyond altruistic and commercial contract pregnancy: The professional model”, Bioethics, No 27: pp. 373-381.

VAN ZYL, Liezl L. y Walker, Ruth (2015): “Surrogate Motherhood and Abortion for Fetal Anormality", Bioethics, No 29: pp. 529-535.

Van Zyl, Liezl L. y Walker, Ruth (2017): Towards a Professional Model of Surrogate Motherhood (United Kingdom, Palgrave Macmillan).

VegA, Javier y OrTega, Íñigo (2007): "La 'pendiente resbaladiza' en la eutanasia en Holanda”, Cuadernos de Bioética, Vol. XVIII, No 62: pp. 89-104.

Vela, Antonio José (2017): “¿En serio? Yo alucino con el comité. A propósito del 'Informe del Comité de Bioética de España sobre los aspectos éticos y jurídicos de la maternidad subrogada' de 19 de mayo de 2017”, Diario La Ley, No 9035, de 6 de septiembre de 2017: pp. 1-20.

VILAR, Silvia (2014): "Situación actual de la gestación por sustitución”, Revista de Derecho UNED, No 14: pp. 897-937. 


\section{JURISPRUDENCIA CITADA}

Tribunal Europeo de Derechos Humanos. Caso Mennenson contra Francia (Ap. No 65192/11) y Labasse contra Francia (Ap. No 65941/11).

España. Tribunal Supremo (Sala de lo Civil. Pleno). Sentencia núm. 835/2013 de 6 de febrero de 2014. Ponente: Rafael Saraza Jimena

España. Tribunal Supremo (Sala de lo Civil. Primera). Auto núm. 245/2012 de 2 de febrero de 2015. Ponente: Rafael Saraza Jimena

España. Tribunal Supremo (Sala de lo Social. Pleno). Sentencia núm. 881/2016, de 25 de octubre de 2016. Ponente: Antonio Vicente Sempere Navarro.

Portugal. Tribunal Constitucional (Pleno). Sentencia No 225/2018. Ponente: Conselheiro Pedro Machete. Diário da República $1^{\text {a }}$ serie, No 87 de 7 de mayo de 2018. Disponible en https://dre.pt/web/guest/home/-/dre/115226940/details/ maximized?serie $=I \&$ day $=2018-05-07 \&$ date $=2018-05-01$. Fecha de consulta: 17 de mayo de 2018.

\section{NORMAS CITADAS}

LEY 14/2006, de 26 de mayo, sobre técnicas de reproducción humana asistida.

Real Decreto 295/2009, de 6 de marzo, por el que se regulan las prestaciones económicas del sistema de la Seguridad Social por maternidad, paternidad, riesgo durante el embarazo y riesgo durante la lactancia natural.

Real Decreto 1723/2012, de 28 de diciembre, por el que se regulan las actividades de obtención, utilización clínica y coordinación territorial de los órganos humanos destinados al trasplante y se establecen requisitos de calidad y seguridad.

Real Decreto Legislativo 8/2015, de 30 de octubre, por el que se aprueba el texto refundido de la Ley General de la Seguridad Social.

Instrucción 5 de octubre de 2010, de la Dirección General de los Registros y del Notariado, sobre régimen registral de la filiación de los nacidos mediante gestación por sustitución.

Proposición de Ley reguladora del derecho a la gestación por subrogación. Boletín Oficial de las Cortes Generales, núm. 145-1, de 8 de septiembre de 2017. 
